\title{
Morphometric Study of the Jugular Foramen in Northwest Indian Population
}

\author{
Anjali Singla, Daisy Sahni, Anjali Aggarwal, Tulika Gupta, Harjeet Kaur
}

\section{ABSTRACT}

Context: Most of the approaches for skull base surgeries are designed to drill the bone around the jugular foramen for proper exposure. In order to achieve this, an understanding of normal morphometric dimensions of jugular foramen is necessary.

Aim: To conduct the morphometric analysis and anatomical variations of jugular foramen (JF) in Northwest Indian population.

Settings and design: Anatomic study using human skulls.

Materials and methods: Anteroposterior and mediolateral diameter of jugular foramen, depth (if domed) and width of jugular fossa were measured with the help of digital vernier caliper.

Statistical analysis used: The mean, standard deviation (SD) and range of each dimension was computed. A comparison between right and left jugular foramina was made by using student's t-test.

Results: Mediolateral diameter of jugular foramen and width of jugular fossa was significantly higher on the right side. An abnormal unilateral blockage of jugular foramen by a bone growth converting it into a slit was noted with anteroposterior (AP) diameter of $2.37 \mathrm{~mm}$ in one skull. Bilateral complete septation of jugular foramen into two and three compartments was observed in $2(4 \%)$ and $3(6 \%)$ of the skulls respectively. The domed bony roof was noticed in $66 \%$ of the skulls on both the sides.

Conclusion: The observed variations of JF are possibly due to constitutional, racial or genetic factors. Knowledge of the observed variations of this foramen may be important for neurosurgeons, radiologists and anthropologists.

Keywords: Jugular foramen, Jugular fossa, Septation, Skull.

Key message: The total subdivision of jugular foramen is not common in our environment. The jugular foramen is generally larger on right side. This study supports reported morphometric variations of jugular foramen, besides adding data on the Northwest Indian population.

Abbreviation: CC: carotid canal; BO: basi-occiput; OC: occipital condyle; JF: jugular foramen; S: styloid process.

How to cite this article: Singla A, Sahni D, Aggarwal A, Gupta T, Kaur H. Morphometric Study of the Jugular Foramen in Northwest Indian Population. J Postgrad Med Edu Res 2012;46(4):165-171.

Source of support: Nil

Conflict of interest: None declared

\section{INTRODUCTION}

Tumors involving the jugular foramen and adjacent structures require a microsurgical approach to this region. ${ }^{1,2}$
Most of the surgical approaches are designed to drill the bone around the jugular foramen for proper exposure. ${ }^{3-5}$ Also the neoplastic pathologies tend to alter the normal anatomy of jugular foramen by invasion, erosion or expansion. ${ }^{6,7}$ Therefore it may not be possible to have correct anatomic visualization of jugular foramen region in the presence of such pathology. Thus, the knowledge of relevant anatomical details and dimensions of jugular foramen in the regional population would be of great help to surgeon while approaching these lesions.

\section{MATERIALS AND METHODS}

One hundred jugular foramina of 50 adult dry skulls of unknown sex were examined.

\section{Jugular Foramen}

- Anteroposterior diameter (AP) of jugular foramenmaximum anteroposterior diameter of jugular foramen was measured.

- Mediolateral diameter (ML) of jugular foramen-this diameter was taken between medial-most and lateralmost point of the jugular foramen (Fig. 1).

- Bony septum - incidence of bony septum was observed. If complete, the number of complete septa and compartments of foramen were also observed.

\section{Jugular Fossa}

- Width of jugular fossa-maximum width of jugular fossa was measured.

- Presence or absence of domed bony roof was noted.

- Depth of jugular fossa-if domed, depth of the jugular fossa was measured from the summit of dome to inferior border of jugular fossa.

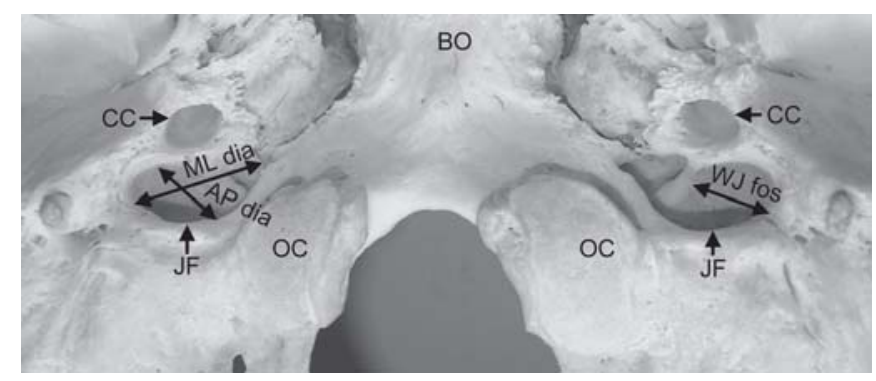

Fig. 1: The metric measurements of the jugular foramen, ML diamediolateral diameter of jugular foramen, AP dia-anteroposterior diameter of jugular foramen, WJ fos-width of jugular fossa 
The measurements were taken in millimeters with the help of Mitutoyo digimatic vernier caliper (accuracy up to $0.02 \mathrm{~mm})$.

All the measurements were taken bilaterally.

Statistical analysis was performed with SPSS version 11 . The mean, standard deviation (SD) and range of each dimension was computed. A comparison between right and left jugular foramina was made by using Student's t-test.

\section{RESULTS}

On examination of the skulls it became apparent that most of the foramina were surmounted by domed bony roof, complete division of foramen by a bony septum was found to be a rare feature. The mediolateral diameter of the foramen was more than the anteroposterior diameter, with most of the foramina having AP and ML diameter between 5 to 10 and 12 to $17 \mathrm{~mm}$ respectively.

\section{Jugular Foramen}

- Anteroposterior diameter of jugular foramen: Mean AP diameter on the right and left side was found to be $9.32 \mathrm{~mm}$ and $7.34 \mathrm{~mm}$ respectively (Table 1 ). It was found that $71 \%$ of total foramina were having AP diameter between 5 and $10 \mathrm{~mm}$. A few of them, i.e. $6 \%$ were having narrow jugular foramen with AP diameter less than $5 \mathrm{~mm}$; most of these narrow foramina belonged to left side, 23\% were having AP diameter more than
$15 \mathrm{~mm}$ (Fig. 2). Comparison between the right and left side of the skulls showed a significant difference, the right being larger ( $p=0<0.05$ ). A slit-like jugular foramen was observed in one skull on left side with AP diameter of $2.37 \mathrm{~mm}$ and ML diameter was $13.45 \mathrm{~mm}$ (Fig. 3).

- Mediolateral diameter of jugular foramen: Average ML diameter was found to be 15.67 and $14.85 \mathrm{~mm}$ on the right and left side, but statistically no significant difference was observed between the two sides $(p=0.06>0.05)$. Most of the foramina, i.e. $72 \%$ were found to have ML diameter between 12 and $17 \mathrm{~mm}, 6 \%$ between 7 to $12 \mathrm{~mm}$ and $22 \%$ were noted to have more than $17 \mathrm{~mm}$.

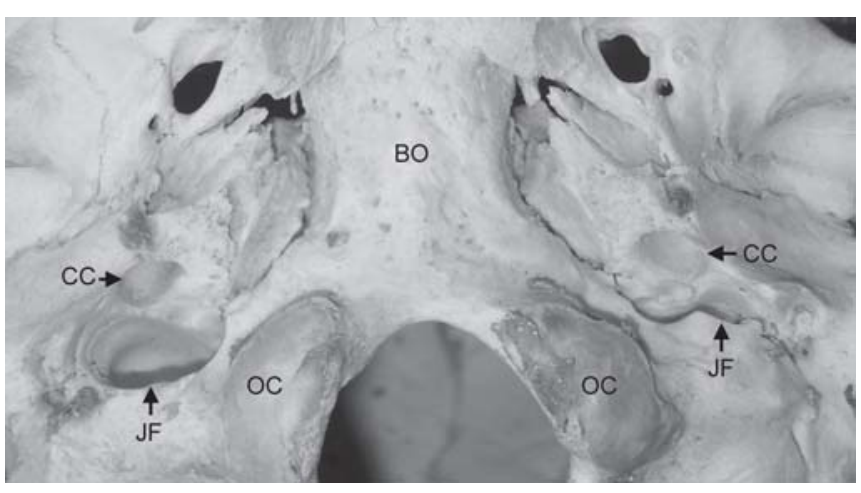

Fig. 3: The slit-like jugular foramen on the left side (anteroposterior diameter-2.37 $\mathrm{mm}$ )

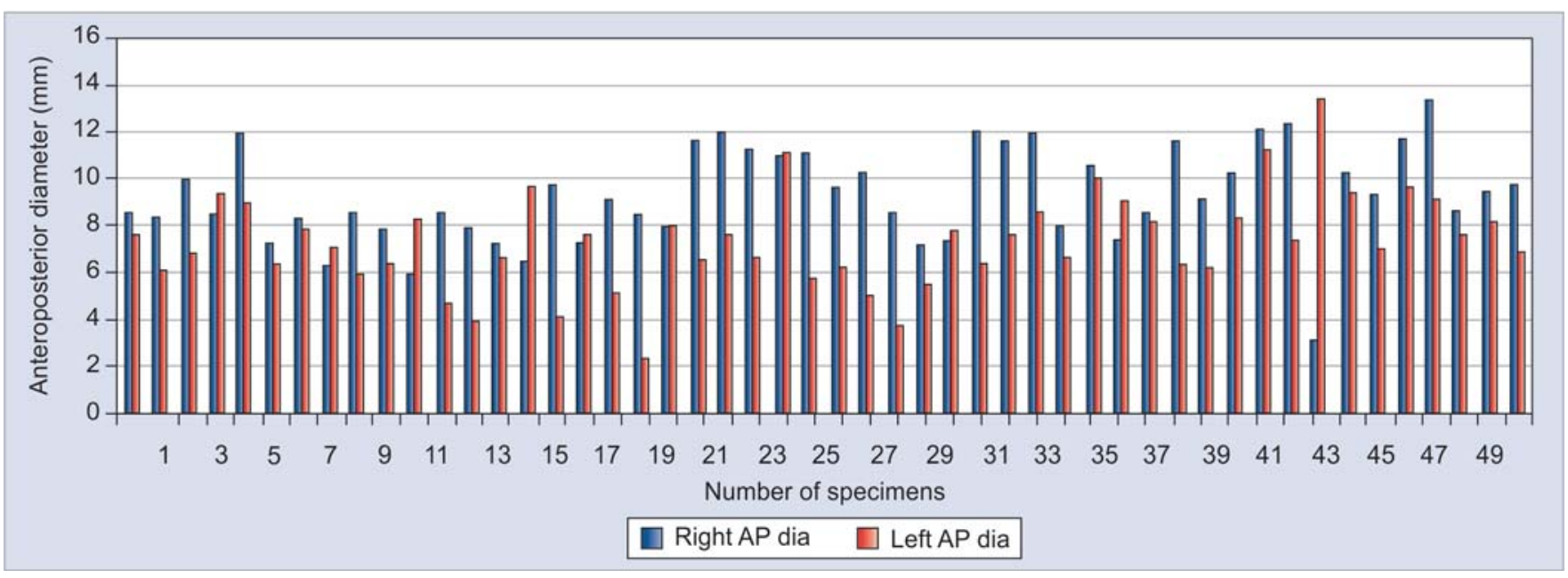

Fig. 2: The anteroposterior diameters of jugular foramen on right and left side

\begin{tabular}{|c|c|c|c|c|c|}
\hline \multirow[t]{2}{*}{ Parameters } & \multicolumn{2}{|c|}{ Right jugular foramen } & \multicolumn{3}{|c|}{ Left jugular foramen } \\
\hline & Range & Mean $\pm S D$ & Range & Mean $\pm S D$ & $t$-test \\
\hline AP dia-jugular foramen ( $\mathrm{mm}$ ) & $3.19-13.4$ & $9.32 \pm 2.04$ & $2.37-13.44$ & $7.34 \pm 2.04$ & $0.00^{*}$ \\
\hline ML dia-jugular foramen ( $\mathrm{mm}$ ) & $10.86-22.7$ & $15.67 \pm 2.28$ & $7.29-22.95$ & $14.85 \pm 2.89$ & 0.06 \\
\hline Width-jugular fossa (mm) & $5.62-14.62$ & $8.99 \pm 1.92$ & $3.05-13.5$ & $7.54 \pm 2.07$ & $0.00^{*}$ \\
\hline Depth of jugular fossa (mm) & $5.41-17.85$ & $11.11 \pm 2.96$ & $3.77-24.23$ & $11.04 \pm 3.75$ & 0.97 \\
\hline
\end{tabular}

${ }^{*} p<0.01$ 
- Presence of septa: Jugular foramen is normally divided into three compartments by two marked constrictions partially. Complete partition is not a common feature. In our study we observed the bilateral complete septation of jugular foramen into two and three compartments in 2 (4\%) and $3(6 \%)$ of the skulls respectively. Whereas unilateral (right) septation into two compartments was observed in 2 (4\%) skulls only (Figs 4A to C). Partial septation was observed in rest of the skulls.

\section{Jugular Fossa}

- Width of jugular fossa: Mean width of jugular fossa was found to be 8.99 and $7.54 \mathrm{~mm}$ respectively on right and left side. About $77 \%$ of fossae were having width in the

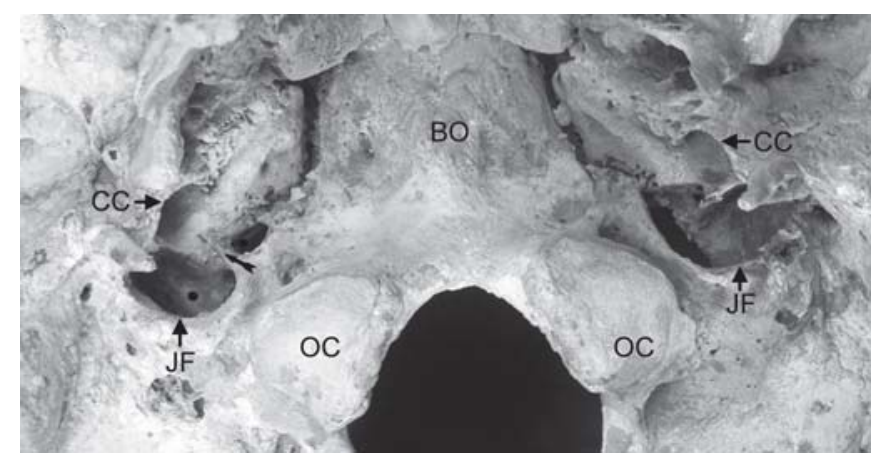

Fig. 4A: The unilateral complete partition of the jugular foramen into two compartments (right side). depicts the compartments $\Rightarrow$ indicates the complete partition of jugular foramens

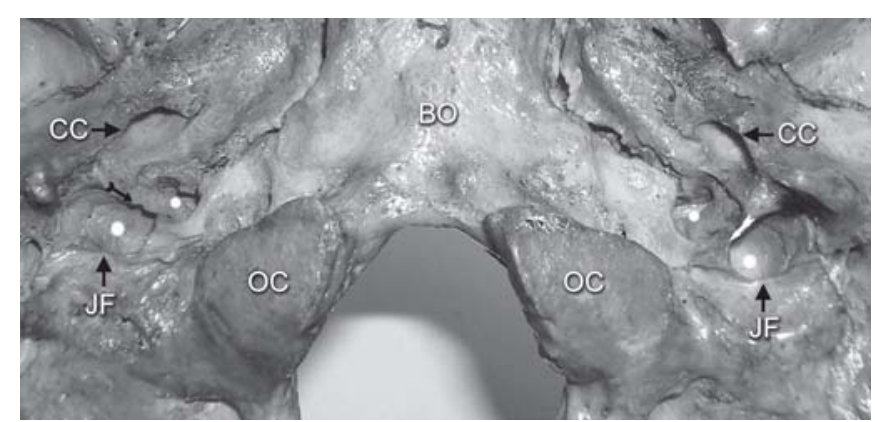

Fig. 4B: The bilateral complete partition of jugular foramen into two compartments. Depicts the compartments indicates the complete partition of jugular foramen

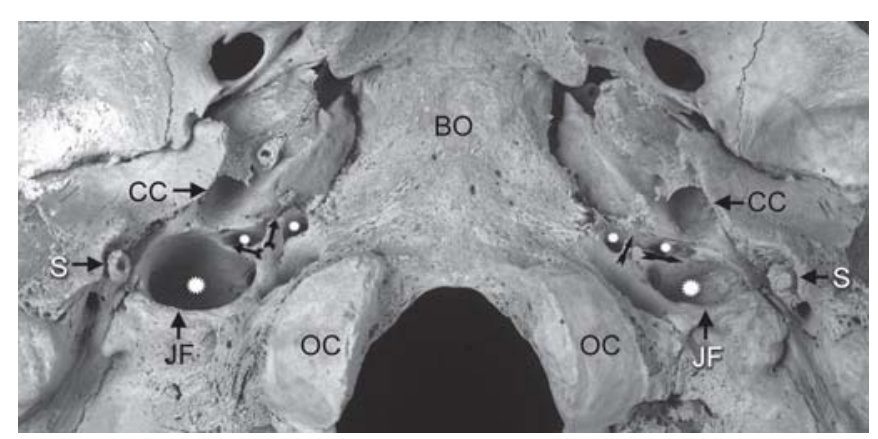

Fig. 4C: The bilateral complete partition of the jugular foramen into three compartments. Depicts the compartments $\boldsymbol{m}$ indicates the complete partition of jugular foramen range of 5 to $10 \mathrm{~mm}, 17 \%$ between 10 and $15 \mathrm{~mm}$ and only $6 \%$ were with less than $5 \mathrm{~mm}$. Statistically a significant difference was found between the right and left side, right side showing the larger measurement ( $\mathrm{p}=0<0.05)$.

- Dome of jugular fossa: A dome indicating the presence of a prominent superior jugular bulb was present bilaterally in 33 skulls (66\%), on the right side only in 3 (6\%) skulls (Fig. 5) and on the left in 8 (16\%) skulls. Whereas the dome was absent bilaterally in $6(12 \%)$ of the total skulls.

- Depth of jugular fossa: Depth of the fossa was measured, if the fossa had a doomed roof. In our investigation doomed roof was observed in $72 \%$ on right side and $82 \%$ on left side. Mean depth on the right and left was measured to be 11.11 and $11.04 \mathrm{~mm}$ respectively. Most of the foramina were having depth between 5 and $15 \mathrm{~mm}$ (Fig. 6). But one extreme of normal variation was very deep tunnel like fossa which was found with a depth of $24.23 \mathrm{~mm}$ on the left side (Fig. 7).

\section{DISCUSSION}

The shape and size of the jugular foramen is related to the size of the internal jugular vein and the presence or absence of a prominent superior bulb. Standard anatomical textbooks describe the superior sagittal sinus to be draining into the right transverse sinus, thus right foramen is expected to be larger than the left. But there is a very wide variation in the anatomy of the intracranial venous sinuses which accounts for variations in size and shape of jugular foramen. ${ }^{8}$ The difference in the size of the two internal jugular veins, when present, is visible during development at $23 \mathrm{~mm}$ stage of embryo; which might result from different developmental pattern of right and left brachiocephalic veins. ${ }^{9}$

Pereira et $\mathrm{l}^{10}$ found mean AP diameter to be $9.21 \pm 1.95 \mathrm{~mm}$ and $8.65 \pm 1.57 \mathrm{~mm}$ and ML diameter to be $15.82 \pm 2.67 \mathrm{~mm}$ and $15.86 \pm 2.64 \mathrm{~mm}$ on right and left side respectively in Southern Brazilian population. The authors further described that AP diameter was significantly larger on right side which may be related to prominent superior bulb of internal jugular vein. In an another study, Idowu $^{11}$ reported the mean AP diameter to be 10.02 and $9.57 \mathrm{~mm}$ and $\mathrm{ML}$ diameter 13.9 and $14.11 \mathrm{~mm}$ on right and left side respectively. Our findings of these diameters of right $\mathrm{JF}$ are very near to findings given by Pereira et $\mathrm{al}^{10}$ but slightly more than those given by Idowu. ${ }^{11}$ Anteroposterior diameter of the Jugular foramen on the right side is comparable with the value given by Idowu ${ }^{11}$ but we found comparatively lesser value of AP diameter on left side comparing with these studies. 
An unusual finding of a slit-like jugular foramen on the left side with AP and ML dimesions of 2.47 and $7.74 \mathrm{~mm}$ respectively was reported by Rastogi and Budhiraja. ${ }^{12}$ In our series also, there was a solitary skull with a slit like jugular foramen with AP and ML diameter of 2.37 and $13.45 \mathrm{~mm}$ respectively. So ML diameter of this slit-like jugular foramen in our study was almost double than as reported by Rastogi and Budhiraja. ${ }^{12}$ Due to narrowing of foramen IX, X and XI cranial nerves may get involved resulting in Vernet's syndrome. It might cause the neurovascular symptoms which can mimic the symptoms of jugular meningiomas, glomus jugular tumors and even a nodule reducing size of jugular foramen in varicella-zoster virus infection. ${ }^{13}$

The average width of jugular fossa in the present study was found to be 8.99 and $7.54 \mathrm{~mm}$ on the right and left side respectively thus occupying almost more than half of the total width of ML diameter of the foramen. Statistically a significant difference was noted between right and left side, right being larger $(\mathrm{p}=0<0.05)$. The width of jugular fossa may be related to the size of internal jugular vein which occupies this fossa. Thus, it can be extrapolated that right jugular vein is comparatively larger. In literature no

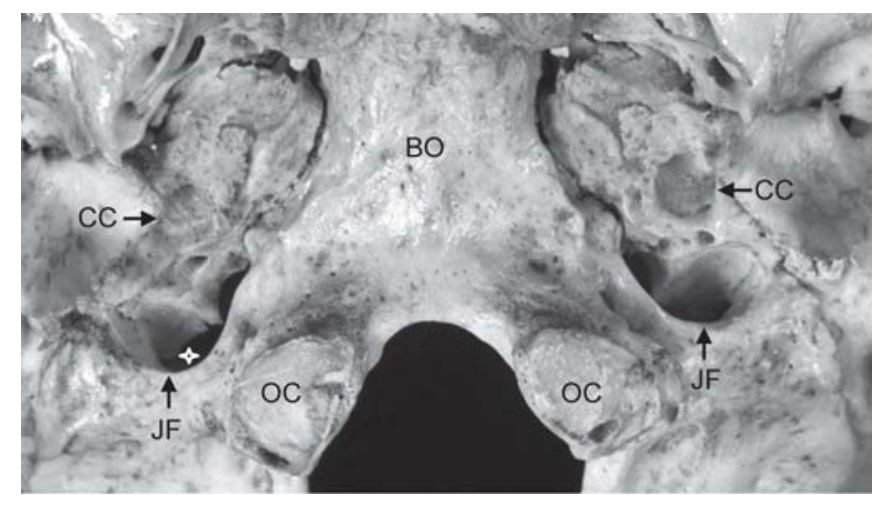

Fig. 5: The absence of the domed roof of jugular fossa on the right side. indicates the absence of domed roof

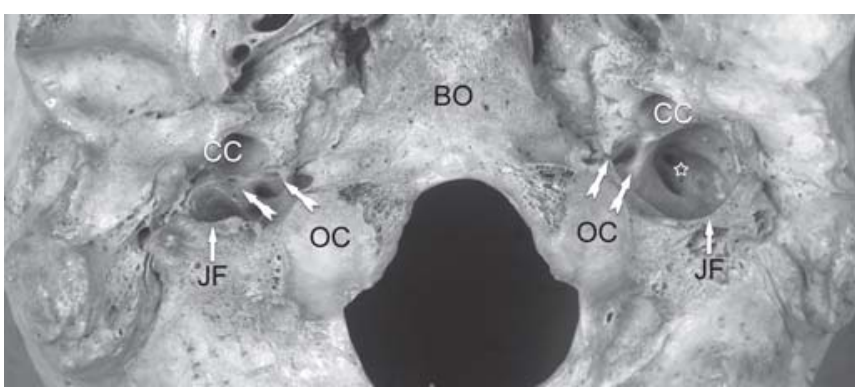

Fig. 7: The deep tunnel like jugular fossa on the left side (depth $24.23 \mathrm{~mm}$ ). indicates the depth of jugular fossa indicates the complete partition of jugular foramen (CC: carotid canal; BO: basiocciput; OC: occipital condyle; JF: jugular foramen; S: styloid process)

comparative data are available for width of jugular fossa as per our knowledge.

Anson ${ }^{14}$ noted the depth of jugular fossa to range from 0-14 mm with most of the specimens with less than $7 \mathrm{~mm}$. But in our investigation most of the cases were having a depth between 5 and $15 \mathrm{~mm}$ (mean $11 \mathrm{~mm}$ ). Extreme variation was noted in one case with a depth of $24.23 \mathrm{~mm}$ on the left side which was even more than double the average depth of fossa. Complete bilateral partition of the foramen into three compartments and the dehiscence of the jugular fossa was also noted in this case. This depth may be related to high jugular bulb causing conductive hearing loss because of its contact with tympanic membrane causing interference with ossicular chain and finally resulting in the obstruction of round window niche. The high jugular bulb may also cause complications during cochlear implantation because of its encroachment into middle ear space..$^{15}$ Though rare in general public, the possibility of this variation should be kept in mind in case of middle ear surgery. ${ }^{16}$ High jugular bulb lying in proximity to the internal acoustic meatus may be at risk during surgery for vestibular schwanommas. ${ }^{17}$ Therefore the knowledge of the fact that there are anatomic variations in the depth of jugular fossa, would make the

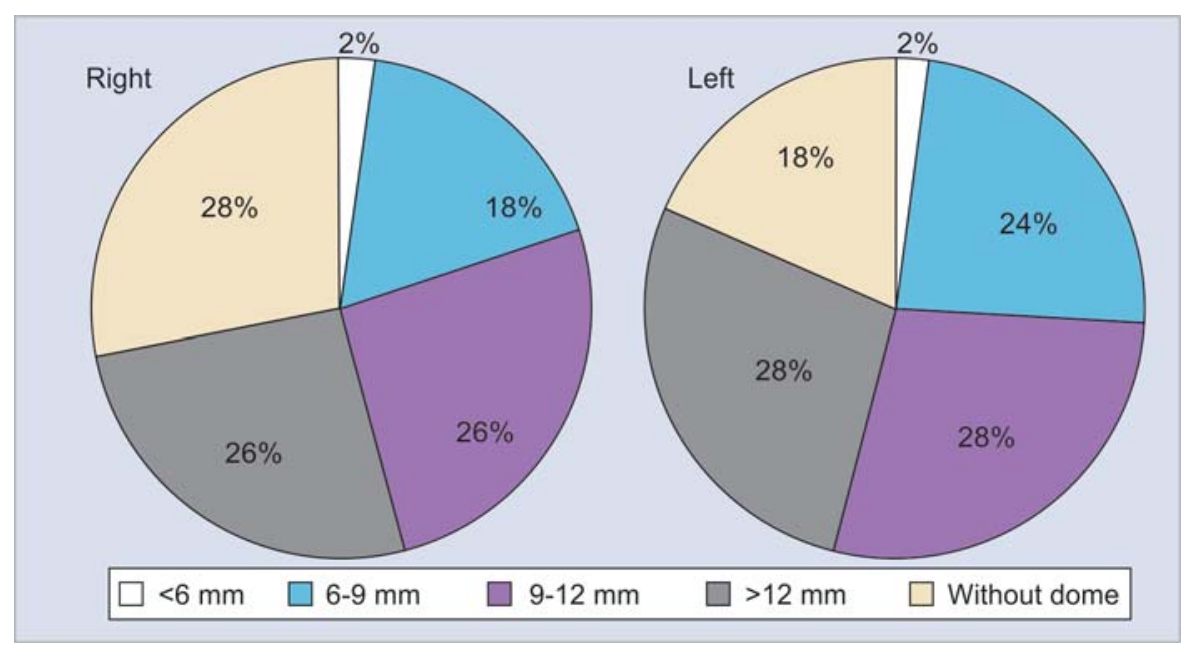

Fig. 6: The depth of the jugular fossa on the right and left side 


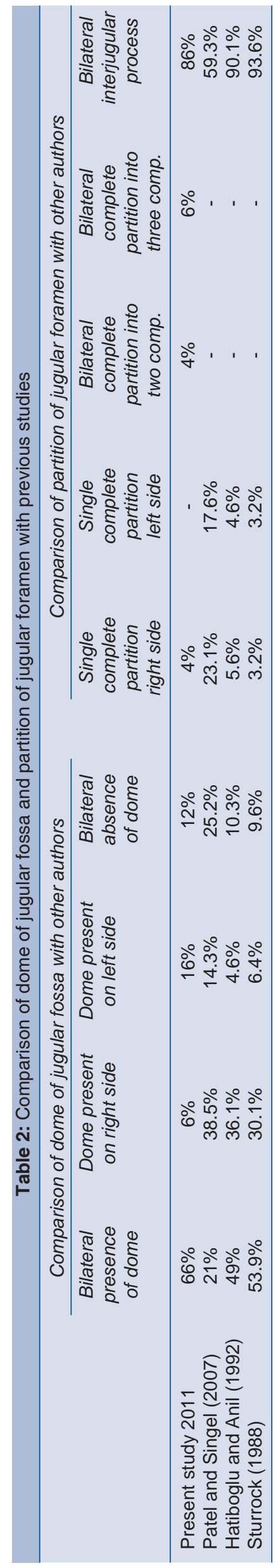


neurosurgeon evaluate these variations prior to any surgical procedure.

The incidence of bilateral domed bony roof in our investigation was $66 \%$ which was comparable to those given by Pereira et $\mathrm{al}^{10}$ who reported bilateral roof in 68.5\%; whereas Sturrock ${ }^{18}$ reported the domed roof on both the sides in 53.9\% and there was a marked difference in another study conducted by Patel and Singel $(2007)^{19}$ who found this feature in only $21 \%$ of the skulls (Table 2 ).

Sturrock ${ }^{18}$ and Hatiboglu and Anil ${ }^{20}$ observed complete septation on right side in $5.6 \%$ of skulls and $3.2 \%$ of the foramina respectively. Pereira et a ${ }^{10}$ observed the bilateral complete bony septum in $0.9 \%$ of cases. In our study complete bilateral and unilateral (Right) septation was observed in 8 and 4\% cases respectively. So the present findings regarding bilateral septation are more than recorded by Pereira et $\mathrm{al}^{10}$ and almost similar to as recorded earlier for unilateral septation (Table 2). Clarifying the morphogenesis of foraminal anamolies at the base of skull, Shapiro and Robonson ${ }^{21}$ stated that three major fenestrations are observed in early human fetal skull-foramen lacerum anterior-hiatus between greater and lesser wing of sphenoid; foramen lacerum medius-opening between basisphenoid and periotic capsule; foramen lacerum posterius-hiatus between basiocciput and the auditory bullae. These openings have their counterpart in the primitive mammalian skull. These large fenestrations become subdivided by the ingrowth of bony spicules, leading to the formation of multiple foramina. The foramen lacerum posterior persists as jugular foramen. Shapiro attributed the variations in the jugular foramen compartmentation to variability in bone formation around primitive foramen lacerum posterior. ${ }^{22}$ It appears that compartmentalization of jugular foramen might be a part of ongoing evolutionary process. ${ }^{23}$

The observed variation of JF is possibly due to constitutional, racial or genetic factors. This study is expected to provide a clear understanding of the jugular foramen anatomy and supports reported morphometric variations of the JF, besides adding data on the northwest Indian population. Anatomical variations especially slit like jugular foramen and jugular fossa with high depth may be the reason for discordant clinical diagnosis. In addition the variations from normal may put the structures of jugular foramen and fossa at risk during microsurgical procedures in this region. So the knowledge of these variations may be important for neurosurgeons, radiologists as well as anthropologists.

\section{ACKNOWLEDGMENT}

The authors thank Mr Vijay Bakshi for photography part.

\section{REFERENCES}

1. Ramina R, Maniglia JJ, Fernandes YB, Paschoal JR, Pfeilsticker LN, Neto MC, et al. Jugular foramen tumors: Diagnosis and treatment. Neurosurg Focus 2004;17(2): 31-40.

2. Matsushima T, Kawashima M, Masuoka J, Mineta T, Inoue T. Transcondylar fossa (supracondylar transjugular tubercle) approach: Anatomic basis for the approach, surgical procedures and surgical experience. Skull Base 2010;20(2)83-91.

3. Gjuric M, Bilic M. Transmastoid-infralabyrinthine tailored surgery of jugular paragangliomas. Skull Base 2009;19(1): 75-82.

4. Borba LA, Araujo JC, De Oliveira JG, Filho MG, Morso MS, Tirapelli LF, et al. Surgical management of glomus jugular tumors: A proposal for approach selection based on tumor relationships with the facial nerve. J Neurosurg 2010;112(1) 88-98.

5. Ladzinski P, Maliszewski M, Kaspera W, Szczygiel M, Tymowski M. Approach to the jugular foramen and related structures - an analysis of the surgical technique based on cadaver simulation. Neurol Neurochir Pol 2011;45(3):260-74.

6. Sanna M, Bacciu A, Falcioni M, Taibah A. Surgical management of jugular foramen schwannomas with hearing and facial nerve function preservation: A series of 23 cases and review of literature. Laryngoscope 2006;116(12)191-204.

7. Zou LB, Jia L, Zhang YR, Chen HF, Hui XH. Microsurgery via modified far-lateral approach for giant dumbbell shaped jugular foramen tumors. Chin J Cancer 2010;29(2)207-11.

8. Woodhall B. Anatomy of the cranial blood sinuses with particular reference to the lateral. Laryngoscope 1939;49: 966-1010.

9. Padget DH. The development of cranial venous system in man, from the viewpoint of comparative anatomy. Contributions to Embryology 1957;36:79-140.

10. Pereira GAM, Lopes PTC, Santos AMPV, Krebs WD. Morphometric aspects of the jugular foramen in dry skulls of adult individuals in Southern Brazil. J Morphol Sci 2010; 27(1):3-5.

11. Idowu OE. The jugular foramen-a morphometric study. Folia Morphol 2004;63:419-22.

12. Rastogi R, Budhiraja V. Slit-like jugular foramen due to abnormal bone growth at jugular fossa-a case report. IJAV 2010;3:74-75.

13. Kawabe K, Sekine T, Murata K, Sato R, Aoyagi J, Kawase Y, et al. A case report of vernet syndrome with varicella zoster virus infection. J Neurol Sci 2008;270:209-10.

14. Anson BJ. Critical distances in the middle and inner ear and in posterior cranial fossa. Trans Am Acad Ophthalmol Otol 1972; 76:108-29.

15. Weiss RL, Zahtz G, Goldofsky E, Parnes H, Shikowitz MJ. High jugular bulb and conductive hearing loss. Laryngoscope 1997;107:321-27.

16. Overton SB, Ritter FN. A high placed jugular bulb in the middle ear: A clinical and temporal bone study. Laryngoscope 1973;83: 1986-91.

17. Gupta T, Gupta SK. Anatomical delineation of a safety zone for drilling the internal acoustic meatus during surgery for vestibular schwanomma by retrosigmoid suboccipital approach. Clin Anat 2009;22:794-99.

18. Sturrock RR. Variations in the structure of the jugular foramen of human skull. J Anat 1988;160:227-30. 
19. Patel MM, Singel TC. Variations in the structure of the jugular foramen of the human skull in Saurashtra region. J Anat Soc India 2007;56(2):34-37.

20. Hatiboglu MT, Anil A. Structural variations in the jugular foramen of the human skull. J Anat 1992;180:191-96.

21. Shapiro R, Robinson F. The foramina of middle fossa: A phylogenetic, anatomic and pathologic study. Am J Roentgenol 1967;101:779-94.

22. Shapiro R. Compartmentation of jugular foramen. J Neurosurg 1972;36:340-43.

23. Athavale SA. Morphology and compartmentation of the jugular foramen in adult Indian skulls. Surg Radiol Anat 2010;32: 447-53.

\section{ABOUT THE AUTHORS}

\section{Anjali Singla}

Senior Research Fellow, Department of Anatomy, Postgraduate Institute of Medical Education and Research, Chandigarh, India

\section{Daisy Sahni (Corresponding Author)}

Professor and Head, Department of Anatomy, Postgraduate Institute of Medical Education and Research, Chandigarh, India e-mail: daisy_sahni@rediffmail.com

\section{Anjali Aggarwal}

Assistant Professor, Department of Anatomy, Postgraduate Institute of Medical Education and Research, Chandigarh, India

\section{Tulika Gupta}

Assistant Professor, Department of Anatomy, Postgraduate Institute of Medical Education and Research, Chandigarh, India

\section{Harjeet Kaur}

Museum Curator, Department of Anatomy, Postgraduate Institute of Medical Education and Research, Chandigarh, India 